\title{
Canadian Urological Association Best Practice Report: Sports and the solitary kidney - What primary caregivers of a young child with a single kidney should know (2019 update)
}

Karen Psooy ${ }^{1}$; Julie Franc-Guimond ${ }^{2}$; Darcie Kiddoo ${ }^{3}$; Armando Lorenzo ${ }^{4}$; Dawn MacLellan ${ }^{5}$

${ }^{1}$ Division of Pediatric Urology, Winnipeg Children's Hospital, Winnipeg, MB, Canada; ${ }^{2}$ Division of Pediatric Urology, Department of Surgery, University of Montreal, QC, Canada; ${ }^{3}$ University of Alberta, Edmonton, AB, Canada; ${ }^{4}$ Division of Urology, The Hospital for Sick Children, Toronto, ON, Canada; ${ }^{5}$ Department of Urology, Dalhousie University, Halifax, NS, Canada

Approved by the Pediatric Urologists of Canada (Feb. 28, 2019)

Cite as: Can Urol Assoc J 2019 June 17; Epub ahead of print. http://dx.doi.org/10.5489/cuaj.6118

Published online June 17, 2019

$* * *$

\section{Background and objectives}

The American Academy of Pediatrics (AAP) provides recommendations regarding sports in the child with a solitary kidney. ${ }^{1}$ They suggest that no restrictions be placed on noncontact sports, and that clinical judgement be used regarding placing any restrictions on contact/collision and limited-contact sports.

A Canadian Urological Association (CUA) guideline on the topic sports and the solitary kidney was initially developed in 2006 in accordance with the 2001 recommendations of the $\mathrm{AAP}^{2}$, tailoring them to the young, sports-naïve child. As per the AAP recommendations, a literature search was carried out to determine what evidence is available on the risks of injury to the paediatric kidney through sports and whether these risks might be lowered through sports modification or use of protective gear. A detailed explanation of this literature search and conclusions are available in the Canadian Journal of Urology, June 2006. ${ }^{3}$ In 2014, the CUA guideline was updated ${ }^{4}$, following a review of updated 2008 AAP recommendations ${ }^{1}$, and repeating the methods as described previously. ${ }^{3}$ The 2014 revision included guidance regarding the operation of all-terrain vehicles. This 2019 revision, produced as a CUA Best Practice Report, was developed following a review of the relevant literature from 2014 to January 2019, and the current position statements of some North American paediatric medical societies. It is noted that there have been no further publications from the AAP on the topic of sports and the solitary kidney since $2012 .^{5}$ 


\section{Recommendations}

In accordance with the AAP recommendations, the following information should be conveyed to the primary caregiver(s) of a young child with a single kidney. Supporting documentation is provided following each statement with level of evidence based on the International Consultation on Urological Diseases (ICUD) system.

\section{following:}

Primary caregivers of a young child with a single kidney should be informed of the

1. Their child has only one kidney and loss of that kidney would result in the need for dialysis or a renal transplant, and lifelong medications

a. Evidence: Indisputable

2. Significant renal injury, of any aetiology, increases the risk/degree of renal insufficiency

a. Evidence - Level 3: High grade renal trauma results in ipsilateral renal scarring and volume loss on DMSA renal scan ${ }^{6}$

3. While renal injury can result from contact/collision or limited contact sports, the risks are less than the risk of head injury

a. Evidence - Level 3: In American football, which is considered a "collision" sport, kidney injuries occur significantly less often than head injuries ${ }^{5}$

b. Evidence - Level 3: Those sporting activities most associated with high-grade renal trauma (bicycling, sledding, downhill skiing, snowboarding and equestrian), have more than a $5 \mathrm{X}$ relative risk of head injury compared to renal injury ${ }^{3}$

4. Primary caregivers should try to keep things in perspective: If they are not going to restrict a child from an activity based on the child having only one "head", then they should not restrict the child from that activity based on having only one kidney

a. Evidence - Level 3: Those activities most associated with high-grade renal trauma (bicycling, sledding, downhill skiing, snowboarding and equestrian), have more than a $5 \mathrm{X}$ relative risk of head injury compared to renal injury ${ }^{3}$

5. Wearing protective padding during contact/collision and limited contact sports may decrease the risk of renal injury

a. Evidence - Level 4: Although protective padding is available, there is no evidence to prove they prevent renal injuries ${ }^{7,8}$

6. The exact risk of renal injury from each sport is unknown; however, according to available studies, bicycling, non-motorized sledding, downhill skiing/snowboarding and horse-related activities may carry a higher risk than other activities ${ }^{3,9,10}$

a. Evidence - Level 3: Review of nine published articles (2000-2005) reporting on paediatric renal trauma in North America shows that bicycling, sledding, downhill skiing, snowboarding and equestrian sports are implicated as the most common sports-related causes of high-grade renal trauma ${ }^{3}$ 


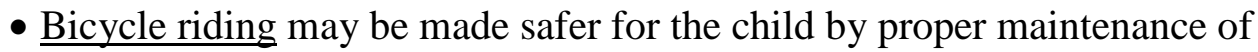
the bicycle and handlebars

1. Evidence - Level 3: Minor bicycle crashes can result in serious handle-bar associated injuries ${ }^{11}$

2. Evidence - Level 4: As falling onto bicycle handlebars results in renal trauma, it is assumed, but not proven, that proper maintenance of the bicycle and handlebars would help prevent renal injuries ${ }^{11}$

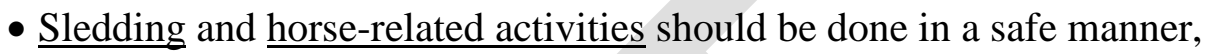
ideally with supervision

1. Evidence - Level 4: Most serious sledding injuries occur when sledding is done near or on roadways, when being towed by a motorized vehicle, or when a stationary object is hit. Therefore it is assumed, but not proven, that renal injuries are less likely if sledding is limiting to non-crowded, designated hills, ideally with parental supervision ${ }^{12,13}$

2. Evidence - Level 4: It is assumed, but not proven, that horserelated injuries might be prevented if: horses and activities are properly matched to the child's capabilities; children avoid standing in positions where they might be kicked; and there is parental supervision ${ }^{14,15}$

- Downhill skiing may be safer than snowboarding. Injuries are more likely to occur in beginners. Formal instruction may be beneficial. Injuries are more likely to occur in inclement weather

1. Evidence - Level 3: When compared, renal injuries were significantly higher in snowboarders than alpine skiers (all ages). ${ }^{16}$ When compared, abdominal injuries were significantly higher in snowboarders than alpine skiers (children) ${ }^{17}$

2. Evidence - Level 3: Injuries are more likely to occur in beginners (all ages) ${ }^{17}$

3. Evidence - Level 3: While the overall risk of injury may not be decreased by formal instruction, the risk of potentially severe injuries may be lowered by taking lessons (all ages) ${ }^{18}$

4. Evidence - Level 3. Overall injury risk is higher when inclement weather effects visibility and snow conditions ${ }^{19}$

7. Motor vehicle collisions (MVCs) are a common cause of paediatric renal injury. Therefore, your child should always be in appropriate car restraints and be taught pedestrian and bicycle road safety 
a. Evidence - Level 3: Review of 7 remote publications (2000-2005), reporting on paediatric renal trauma (all grades) in North America, showed that MVCs (including passenger and pedestrian) resulted in more renal trauma than sporting

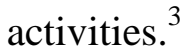

b. Evidence - Level 3. Review of 2 recent publications, reporting on paediatric renal trauma (all grades) between the years of 1993-2014, shows that MVCs (including passenger and pedestrian) were responsible for $16^{20}-19 \%{ }^{21}$ of renal injuries

8. The use of all-terrain vehicles (ATVs) by children is associated with high grade kidney trauma. However, unlike other recreational activities mentioned in this report, some states in the USA have strict regulations regarding ATV use in children, and a number of paediatric medical societies provide formal recommendations against the operation of allterrain vehicles by all children less than 16 years of age, regardless of kidney number

a. Evidence - Level 3: Renal injuries from 2, 3 and 4 wheeled recreational vehicles are associated with higher grade renal injuries than those caused by bicycle injuries. $^{7}$

b. Evidence - Level 3: Massachusetts has strict state regulations regarding ATV use in children. ${ }^{22}$ As such, a Boston paediatric trauma center reported no renal injuries secondary to ATV use over a 20 year period (1994-2014). ${ }^{20}$ This is in comparison to Pennsylvania, where during a similar period (1993-2013), ATV use accounted for $17 \%$ of high grade paediatric trauma ${ }^{21}$

c. Societies recommending against ATV operation in children:

- American Academy of Pediatrics $2018^{23}$

- American Pediatric Surgical Association $2018^{24}$

- Canadian Pediatric Society $2012^{25}$

\section{Summary}

1. The CUA supports the 2008 recommendations of the AAP that suggest that for children with a solitary kidney, no restrictions be placed on noncontact sports, and that clinical judgement be used regarding placing any restrictions on contact/collision and limitedcontact sports

2. Caregivers should be informed about the sports that may carry a higher risk of renal injury and the potential ways to reduce these risks as described in points 5 and 6 above; however, they should also be encouraged to keep things in perspective, as described in point 4 above

3. Children with solitary kidneys should always be placed in appropriate car restraints and be taught pedestrian and bicycle road safety

4. The CUA supports the recommendations of the paediatric societies that recommend against ATV operation in all children as described in point 8 above 


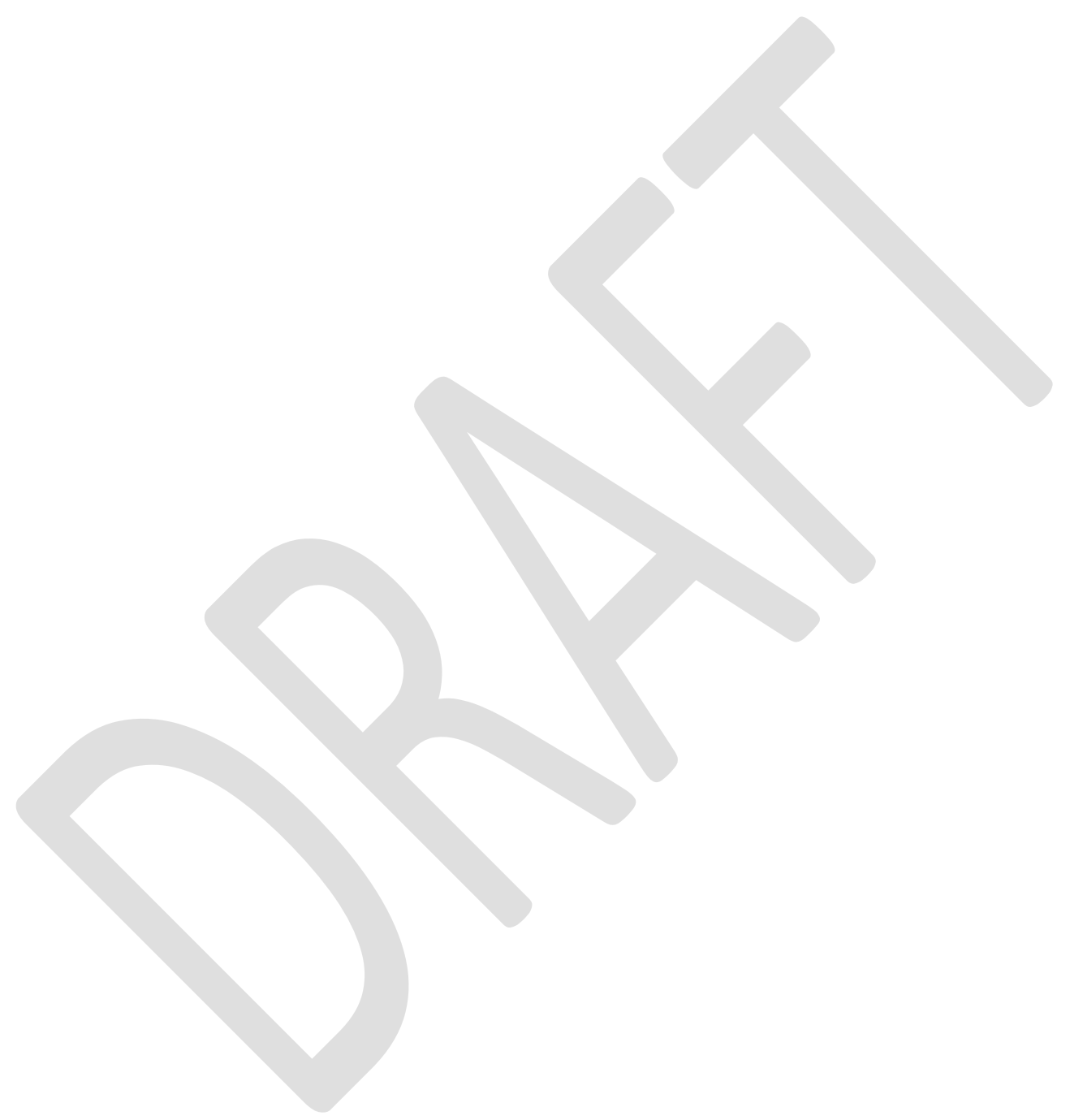




\section{References}

1. Medical conditions affecting sports participation. Rice SG, Council of Sports Medicine an d Fitness. Pediatrics 2008;121:841-848.

2. American Academy of Pediatrics Committee on Sports Medicine and Fitness. Medical conditions affecting sports and participation. Pediatrics 2001;107(5):1205-1209.

3. Psooy K. Sports and the solitary kidney: how to counsel parents. Can J Urol 2006; 13:3034-40.

4. Psooy K. Sports and the solitary kidney: what parents of a young child with a solitary kidney should know. Can Urol Assoc J 2014;8:233-235.

5. Grinsell MM, Butz K, Gurka MJ et al. Sport-related kidney injury among high school athletes. Pediatrics 2012;130:e41-45.

6. Keller MS, Coln CE, Garza JJ, et al. Functional outcome of nonoperatively managed renal injuries in children. J Trauma 2004;57:108-10.

7. Styn NR, Wan J. Urologic sports injuries in children. Curr Urol Rep 2010;11:114-121.

8. Andres S, Bushau-Sprinkle A, Brier M, et al. Effects of body protection vests and experience levels in prevention of equestrian injuries. BMJ Open Sport Exerc Med 2018;4:e000426.

9. Wu H-Y, Gaines BA. Dirt bike and all terrain vehicles: the real threat to kidneys. J Urol 2007;178:1672-1674.

10. Sacco E, Marangi F, Pinto F, et al. Sports and genitourinary trauma. Urologia 2010;77:112-125.

11. Winston FK, Shaw KN, Kreshak AA, et al. Hidden spears: handlebars as injury hazards to children. Pediatrics 1998;102:596-601.

12. Shorter NA, Mooney DP, Harmon BJ. Childhood sledding injuries. Am J Emerg Med 1999;17:32-4.

13. Noffsinger D, Nuss K, Haley K, et al. Pediatric sledding trauma: avoiding the collision. Journal of Trauma Nursing 2008;14:58-61.

14. Jagodzinski T, DeMuri GP. Horse-related injuries in children: a review. WMJ 2005; 104:50-54.

15. Eckert V, Lockemann U, Püschel K, et al. Equestrian injuries caused by horse kicks: first results of a prospective multicenter study. Clin J Sport Med 2011;21:353-355.

16. Wasden CC, McIntosh SE, Keith DS, et al. An analysis of skiing and snowboarding injuries on Utah slopes. J Trauma 2009:67:1022-1026.

17. Polites S, Mao S, Glasgow A, et al. Safety on the slopes: ski versus snowboard injuries in children treated at United States trauma centers. Journal of Pediatric Surgery 2018;53:1024-1027.

18. Sulheim S, Holme I, Rodven A, et al. Risk factors for injuries in alpine skiing, telemark skiing and snowboarding - case control study. Br J Sports Med 2011;45:1303-1309.

19. Hume P, Lorimer A, Griffiths P, et al. Recreational Snow-Sports Injury Risk Factors and Countermeasures: A Meta-Analysis Review and Haddon Matrix Evaluation. Sports Med 2015;45:1175-1190.

20. Armstrong L, Mooney D. Pediatric renal injury: which injury grades warrant close follow-up. Pediatric Surgery International 2018;34:1183-1187. 
21. Dangle P, Fuller T, Gaines B, et al. Evolving mechanisms of injury and management of pediatric blunt renal trauma-20 years of experience. Urology 2016;90:159-163.

22. Mass.gov ohv-pamphlet. Available at https://www.mass.gov/files/documents/2017/10/04/ohvpamphlet.pdf? ga=2.126025231.367968840.1550275826-1059840908.1550275826. Accessed February 15, 2019.

23. ATV Safety Tips from the American Academy of Pediatrics. Available at https://www.aap.org/en-us/about-the-aap/aap-press-room/news-features-and-safetytips/Pages/ATV-Safety-Tips-from-the-AAP.aspx. Accessed February 3, 2019.

24. American Pediatric Surgical Association Trauma Committee position statement on the use of all-terrain vehicles by children and youth. Available at https://www.eapsa.org/getattachment/Resources/For-Professionals/APSA-StatementsGuidelines/All-Terrain-Vehicle-Position-Paper_updated-2018.pdf. Accessed February 3, 2019.

25. Canadian Paediatric Society Position Statement: Preventing injuries from all-terrain vehicles. Available at http://www.cps.ca/en/documents/position/preventing-injury-fromatvs. Accessed February 3, 2019. 